To guess the future of mathematical science would be a rash attempt. If made it might seem that, in view of the extraordinary works of the human intellect which mark our age, the safest cour'se would be to predict great discoveries in this and all other branches of science. The question is sometimes asked whether a mathematical method may not yet be invented which shall be as great an advance on the infinitesimal calculus as the latter was on the methods of Euclid and Diophautus.

So far as solving problems which now confront us is concerned, I am not sure that the safest course would not be to answer such questions in the negative. Is it not true in physics as in mathematics that greut discoveries have been inade on unexpected lines, and that the problems which perplexed our ancestors now baffle our own efforts? We must also remember that the discovery of what could not be done has been an important element in progress. We are met at every step by the irou law of the conservation of energy : in every direction we see the limits of the possible. 'The mathematics of the twenty-first century may be very different from our own; perhaps the schoolboy will begin algebra with the theory of substitution-groups, as he might now but for inherited habits. But it does not follow that our posterity will solve many problems which we have attacked in vain, or invent an algorithm more powerful than the calculus.

\title{
RECENT RESEARCHES IN ELECTRICITY AND MAGNETISM.
}

Notes on Recent Researches in Electricity and Magnetism. Intencled as a sequcl to Professor Clerk-Mix well's "Treatise on Electricity and Mugnetism." By J. J. Thomson, M.A., F.R.S. Oxford, Clarendon Press, 1893. 8vo. pp. 586.

PoIncaré remarks in his "Électricité et Optique" : "I La première fois qu'un lectenr français ouvre le livre de Maxwell, un sentiment de malaise, et souvent même de défiance se méle d'abord à son admiration." And again he says: "Le sarant anglais ne cherche pas à construire un édifice unique, définitif et bien ordonné, il semble plutôt qu'il élèvé un grand nombre de constructions provisoires et indépenduntes, entre lesquelles les communications sont difficiles et quelquefois impossibles." The disconnected way in which Maxwell takes up one hypothesis after another, and then leaves his readers to select for themselves, is naturally abhorrent to a great 
mathematician accustomed to rigorons proof and logical sequence, and especially so to French mathematicians, who, since the tine of Laplace, have certainly been masters of the art of producing clear, logical, and finished treatises. IVe venture to submit, however, that Maxwell's method finds its def'nree, at least in part, in the difference in the attitude of mind of a mathematician and a physicist. In mathematics, a theorem is proved rigorously, and the mind is completely satisfied, feeling that it has arrived at the whole truth of the theorem, wheress in all physical science one hypothesis or theory is simply more probiable than another. Nothing in nuture is subject to rigorous and ultimate proof, and theories are framed from time to time dependent upon the particular state of man's knowledge, yet often contilining so many undeterminerl elements that several entirely different theories account equally well for the observed facts as we know them. 'Thus the probability of the electromagnetic theory of light is nearer unity than the emission theory of Newton, and Maxwell's theory of energy in the medium more probable than action at a distance, yet any theory which may be devised is but an approximation to the whole truth.

The mathematical theory which Maxwell built up twenty yen's ago, after prolound study of Faradiy's experimental re. searches, is mainly responsible for the great advance made in electricity and malgnetism since that time, and his treatise continues to day the source from which the student must seek the great principles of the science

It was fortumate indeed that the Clarendon Press secured Professor 'Thomson's services in revising the proofs for the third edition of Maxwell, which appeared last year, for besides giving to this edition important notes and elucidations, his task determined him to publish a supplementary volume.

Himself an accomplished mathematician as well as a physicist, the anthor brings the resources of analysis to bear upon his researches with consummate skill, while at the sime time he subordinates all to the final test of refined experiment.

The first fifty-two pages of the volume are devoted to the development of a physical method of considering the processes which occur in the electromagnetic field, based upon the properties of Faraday tubes of electrostatic induction in motion. An outline of the method appeared three years ago,* but it was not sufficiently complete to render it easily adaptable to particular cases. Maxwell's conception of displacement is too general in its character to easily vield to a mechanism which will picture to the mind the processes going on in

* J. J. 'Thomson, Phil. Mag., March, 1891. 
the electric field, and this difficulty of comprehending his "displacement" was probably the chief reason why his views were so tardily accepted by physicists.

For this reison the author has devised a method which is mathematically equivalent to Maxwell's, but which is easily grasped by the student, and enables him to form a vivid mental picture of what is going on in any particular case under consideration.

The unit tube is one such that when it terminates on $a$ conductor it corresponds in amount to the charge which in electrolysis we find associated with an atom of is univalent element. All space is supposed to be filled with Furaday tubes floating about, although they may not make themselves manifest on account of their want of arrangement. 'They exist apart from the molecules of the dielectric, have their seat in the ether, and the polarization of the particles of the dielectric is a secondary phenomenon. In the case of open tubes, these must end on matter, and since they join atoms instead of molecules, all electrification is accompanied by chemical dissociation, and the disappearance of it by chemical combination,- - the tubes shortening to molecular dimensions. A Faraciay tube in motion produces: (1) a magnetic force at right angles to the tube and to the direction in which it is moving; (2) a momentum at right angles to the tube and. to the mannetic induction; (3) an electromotive intensity at right angles to the direction of motion and to the magnetic ind uction.

On this theory conduction, whether through gases, electrolytes, or metals, is essentially the same process, and is electrolytic in its character. Many examples in support of this general theory of conduction are given, and apparent exceptions to its application are explained.

Once having clearly given his method, and illustrated it by numerous particular cases, the author uses it constantly throughout the book to assist the student in rapidly getting the main features of the particular problem under consideration. Like Maxwell's treatise itself, we find the book full of suggestions. 'Thus on page 28 we read, "Another question which we have not touched upon, but which is very important, is whether the motion of the Faraday tubes through ether devoid of matter would produce magnetic force, or whether for this purpose it is necessary that the tubes should pass across ordinary matter as well as ether." He then suggests a form of experiment which is a modification of Professor Rowland's Berlin experiment, * for determining this.

* Berichte d. Berlo Acad 1876 p. 211 
Chapter II is one of the most importint and complete in the whole book. It is upon the passage of electricity through gases, and includes one hundred and fifty pages. There is no summary in an English text-book upon the very extensive literature on this subject; and Professor 'Thomson, who is one of the highest anthorities on the discharge through gases, gives an admirable review of the work from the time of Coulomb to the present, and, at the close of the chapter, his theory of the electric discharge. $\Lambda$ s already stated, he believes in the electrolytic theory of discharge, and in fact his general theory of conduction makes the passuge of electricity through guses, electrolytes, and even metuls the sume process. Thie essential results of Crookes, Hittorf, Goldstein, Liebig, De la Rue and Hugo Müller, and Spottiswnode and Monlton, are given and discussed; while the author's own res'arches on the conduct vity of hot gases,* and on the discharge through exhausted tubes without electrodes, $\nmid$ are reproduced almost entire. 'The whole chapter is a splendid bibliography; and physicists at lirge, especially students who may undertake work in any particular phase of this important subject, are indebted to Professor 'I'homson for an immense service.

The mathematical part of the work begins with the chapter on conjugate functions. The method given by Maxwell for the solution of two-dimensional problems in electro-statics by meins of conjugate functions is indirect, and requires the arbitrary assumption of relations between the functions and then seeking for a suitable transformation for the particular case. By the use of a general theorem in trunsformations given by Schivarz $\ddagger$ and Christoffel, $\S$ the proper transformations can be found by a direct process when the lines over which the potential is given are straight.

The theorem is as follows:

'The perimeter of any polygon bounded by strnight lines in a plane, which we cun cull the $z$ plane, where $z=x+i y, x$ and $y$ being the Curtesian coördinates of a point in this pline, can be transformed into the axis of $\xi$ in a plane which we shall call the $t$ pline, where $t=\xi+i \eta, \xi$ and $\eta$ being the Cartesian coürdinates of a point in this plane, points inside the polygon in the $z$ plane transforming into points on one side of the axis of $\xi$.

* Plil. Mag. (5), vol. 29, pp. 358-441, 1890.

+ Phil. Mag.. Oct. 1891 . 1869 .

"Ueber cinige Abbildungsaufgaben," Crelle, vol. 70, pp. 105, 120,

$\$$ Sul problema delle temperature stazionarie, Annali di Matematica, vol, 1,1867 . 
The transformation which effects this is represented by the equation

$$
\frac{d z}{d t}=C\left(t-t_{1}\right)^{\frac{a_{1}}{\pi}-1}\left(t-t_{2}\right)^{\frac{a_{2}}{\pi}-1} \ldots\left(t-t_{r}\right) \frac{a_{r}}{\pi}-1 \ldots\left(t-t_{n}\right) \frac{a_{n}}{\pi}-1,
$$

where $a_{1}, a_{2} \ldots a_{n}$ are the internal angles of the polygon in the $z$ plane; $t_{1}, t_{3} \ldots t_{n}$ are real quantities, and are the coordinates of points on the axis of $\xi$ corresponding to the angular points of the polygon in the $z$ plane.

The application of the theorem is illustrated by the solution of several cases treated by Maxwell and some interesting new ones, while the indirect method is also extended to some simple and beautiful results employing elliptic functions.

Almost the entire remainder of the book is given up to the theoretical and experimental consideration of alternating currents. The great importance which these currents have recently assumed in the industrial world for lighting, and the long-nistance transmission of power, cannot fail to cause this part of the work to be thoronghly appreciated. The chapter on electrical waves and oscillations is an exhaustive treatment of the subject, and many suggestions are given, which will probably serve as starting-points for future investigations.

Alternating currents in two dimensions are first taken up, followed by the more practical case of periodic currents in cylindrical conductors treated generally and in particular cases.

Following the theoretical treatment of the subject comes a chapter on experiments on electromagnetic waves. A very complete account of Hertz's work is given, and the method of Faraday tubes applied in interpreting the results for the various positions of the resonator. An account of Lord Rayleigh's investigations on the laws according to which alternating currents distribute themselves among a network of conductor's, and a discussion of the equations which hold when a dielectric is moving in a magnetic field, complete the volume.

We feel assured that Professor Thomson's supplementary volume will take its proper place beside Maxwell's great treatise in the library of every true student of electrical science.

Grorge 0. SquThr.

Fort MoHment, Mo, November 27, 1893. 